\title{
Author Correction: Differentiated surface fungal communities at point of harvest on apple fruits from rural and peri-urban orchards
}

Youming Shen ${ }^{1,2,3}$, Jiyun $\mathrm{Nie}^{1,2,3}$, Zhixia $\mathrm{Li}^{1,2,3}$, Haifei $\mathrm{Li}^{1,2,3}$, Yonglong Wu ${ }^{1,2,3}$, Yafeng Dong ${ }^{1,2,3}$ \& Jianyi Zhang ${ }^{1,2,3}$

Correction to: Scientific Reports https://doi.org/10.1038/s41598-017-17436-5, published online 01 February 2018

The Acknowledgements section in this Article is incomplete.

“This work was supported by the National Program for Quality and Safety Risk Assessment of Agricultural Products of China (No. GJFP2016003) and the Agricultural Science and Technology Innovation Program of Chinese Academy of Agricultural Sciences (No. CAAS-ASTIP). We acknowledge Shanghai Personal Biotechnology Co., Ltd. (Shanghai, China) for their help in sequencing and bioinformatics analysis."

should read:

“This work was supported by the National Program for Quality and Safety Risk Assessment of Agricultural Products of China (No. GJFP2016003), the Agricultural Science and Technology Innovation Program of Chinese Academy of Agricultural Sciences (No. CAAS-ASTIP), and the Earmarked Fund for China Agriculture Research System (No. CARS-27). We acknowledge Shanghai Personal Biotechnology Co., Ltd. (Shanghai, China) for their help in sequencing and bioinformatics analysis."

(c) (i) Open Access This article is licensed under a Creative Commons Attribution 4.0 International License, which permits use, sharing, adaptation, distribution and reproduction in any medium or format, as long as you give appropriate credit to the original author(s) and the source, provide a link to the Creative Commons license, and indicate if changes were made. The images or other third party material in this article are included in the article's Creative Commons license, unless indicated otherwise in a credit line to the material. If material is not included in the article's Creative Commons license and your intended use is not permitted by statutory regulation or exceeds the permitted use, you will need to obtain permission directly from the copyright holder. To view a copy of this license, visit http://creativecommons.org/licenses/by/4.0/.

(C) The Author(s) 2018

${ }^{1}$ Institute of Pomology, Chinese Academy of Agricultural Sciences, Xingcheng, 125100, P.R. China. ${ }^{2}$ Laboratory of Quality \& Safety Risk Assessment for Fruit (Xingcheng), Ministry of Agriculture, Xingcheng, 125100, P.R. China. ${ }^{3}$ Quality Inspection and Test Center for Fruit and Nursery Stocks (Xingcheng), Ministry of Agriculture, Xingcheng, 125100, P.R. China. Correspondence and requests for materials should be addressed to J.N. (email: jiyunnie@163.com) 